\title{
Vocabulary research in 1983: A bibliometric analysis
}

\author{
Paul Meara \\ Swansea University, the United Kingdom
}

\begin{abstract}
This paper belongs to a series of studies devoted to L2 vocabulary research which has been published in the last fifty years. It follows on directly from my earlier analysis of the $1982 \mathrm{data}$, and attempts to broaden the base line on which the later research developed. The paper presents a brief bibliometric analysis of L2 vocabulary research published in 1983. The analysis identifies a number of research clusters that were not present in the 1982 research but will become significant in later years, and highlights the volatility of vocabulary research at this time.
\end{abstract}

Keywords: L2 vocabulary acquisition, vocabuary research, bibliometric analysis

\section{Introduction}

This paper is the third in a series of studies which attempt to plot the way research in L2 vocabulary acquisition has progressed in the last fifty years. Earlier papers have analysed the research output for 1982 and 2006 (Meara 2012, 2014). This paper follows on directly from my earlier analysis of the 1982 data, and attempts to broaden the base line on which the later research developed. The analysis uses as raw data the pattern of co-citations among the references listed at the end of each of the papers in a small corpus of research published in 1983, and converts these patterns into maps which display how the citations cluster. This form of analysis has been extensively described in the earlier papers, but for readers who are not familiar with this approach, a short summary of the method is provided in Appendix 1.

\section{Background}

The field of L2 vocabulary research in 1983 was somewhat more active than it had been in 1982 . The VARGA database (Meara n.d.) lists a total of 41 papers published in 1982; in 1983, the number of outputs had increased to 70 - an increase of just over $70 \%$. Four of these outputs were doctoral theses, masters theses or other unpublished sources and two (French Allen 1983 and Nation 1983c) were book length treatments, which are by tradition not included in bibliometric analyses of the sort used here. Galisson (1983) was also a book: it contained three 
chapters, two of which had previously been published. The third chapter of this book was new material, and is included in the analysis. A small number of other papers proved to be unobtainable, and were not included in the analysis reported in this chapter. Two papers were published twice in separate locations. The remaining 60 sources are listed in Table 1.

Table 1: The 60 sources used in the analysis

\author{
Adjemian, C \\ The transferability of lexical properties. In: S Gass and L Selinker (Eds.) Language Transfer in Language \\ Learning. Rowley, Mass.: Newbury House. 1983. \\ af Trampe, $P$ \\ An experiment in foreign language vocabulary learning. Concept learning and memorization. Papers from the \\ Institute of Linguistics, University of Stockholm 45, 1983. \\ af Trampe, $\mathbf{P}$ \\ Foreign language vocabulary learning - a criterion of learning achievement. In: H Ringbom (Ed.) \\ Psycholinguistics and Foreign Language Learning. Åbo: Åbo Akademi. 1983.
}

\title{
Altenberg, E and H Cairns
}

The effects of phonotactic constraints in lexical processing in bilingual and monolinguals subjects. Journal of Verbal Learning and Verbal Behavior 22(1983), 174-188.

\section{Ard, J and T Homburg.}

Verification of Language Transfer. In: SM Gass and L Selinker (Eds). Language Transfer in Language Learning. Amsterdam: Benjamins. 1983.

\section{Aronsson, K}

Free recall of mixed language lists: error patterns in bilingual memory. In: H Ringbom (Ed.) Psycholinguistics and Foreign Language Learning. Abo: Abo Akademi. 1983.

\section{Binon, J and A-M Cornu}

La place de l'acquisition du vocabulaire dans l'enseignement du français langue étrangère. [The place of vocabulary in teaching French as a foreign language]. Romaneske 4(1983).

\section{Burling, $\mathbf{R}$}

A proposal for computer-assisted instruction in vocabulary. System 11 2(1983), 181-190.

\section{Carter, $\mathbf{R}$}

A note on core vocabulary. Nottingham Linguistics Circular, 11, 2(1983), 39-50. Nottingham Linguistics Circular 11, 2(1983), 39-50.

\section{Carter, $\mathbf{R}$}

'You look nice and weedy these days': lexical associations, lexicography and the foreign language learner. Journal of Applied Language Study 1, 2(1983), 172-189.

\section{Cornu, A-M and J Binon}

La place de l'acquisition du vocabulaire dans l'enseignement du français, langue étrangère. [The place of vocabulary acquisition in the teaching of French as a foreign language.] Romaniac 10-11(1983), 97-131.

\section{Corson, DJ}

The Corson measure of passive vocabulary. 26(1983), 3-20

\section{Cowie, AP}

The pedagogical/learner's dictionary. In: RK Hartmann (ed.) Lexicography: principles and practice. London: Academic Press. 1983. 135-144.

\section{Cunningsworth, A}

Making vocabulary links. Practical English Teaching 3, 4(1983), 19-20. 


\section{Delay, D}

La mémorisation des mots en classe. Bulletin CILA, 38(1983), 97-105.

\section{Favreau, M and N Segalowitz}

Automatic and controlled processes in the first- and second-language reading of fluent bilinguals. Memory and Cognition 11,6(1983), 565-574.

\section{Galisson, $\mathbf{R}$}

Des mots pour communiquer: elements de lexicomethodologie. Paris: CLE. 1983. (Chapter III was included in the analysis.)

\section{Galloway, L}

Etudes cliniques et experimentales sur la repartition hemispherique du traitement cerebrale du langage chez les bilingues: modeles theoriques. [Clinical and experimental studies of how language is shared between the two hemispheres of the bilingual's brain: some theoretical models.] Langages 72(1983), 79-124.

\section{Goldstein, $\mathbf{H}$}

Word recognition in foreign language: a study of speech perception. Journal of Psycholinguistic Research, 12,4(1983), 414-427.

\section{Harlech-Jones, B}

ESL proficiency and a word frequency count. English Language Teaching Journal 37,1(1983), 62-70.

\section{Harvey, M}

Vocabulary learning: the use of grids. English Language Teaching Journal 37,3(1983), 243-246.

\section{Heikkinen, $\mathbf{H}$}

Errors in lexical processing. In: H Ringbom (Ed.) Psycholinguistics and Foreign Language Learning. Åbo: Åbo Akademi, 1983.

\section{Ilson, $\mathbf{R}$}

Etymological information: can it help our students? English Language Teaching Journal 37,1(1983), 76-81.

\section{Kotsinas, U-B}

On the acquisition of vocabulary in immigrant Swedish. In: H Ringbom (Ed.) Psycholinguistics and Foreign Language Learning. Abo: Abo Akademi. 1983.

\section{Levin, JR, M Pressley, N Digdon, SL Bryant and K Ray}

Does method of item presentation affect keyword method effectiveness? Journal of Educational Psychology 75,5(1983), 686-691.

\section{Linnarud, $M$}

On lexis: the Swedish learner and the native speaker compared. In: K Sajavaara (Ed.) Cross language analysis and second language acquisition. Jyvaskyla. 1983. 249-261.

\section{MacFarquhar, PD and JC Richards}

On dictionaries and definitions. RELC Journal 14,1(1983), 111-124.

\section{Meara, PM}

Word recognition in foreign languages. In: A Pugh and J Ulijn (Eds.) Reading for Professional Purposes. London: Heinemann. 1983.

\section{Meara, PM}

Word associations in a second language. Nottingham Linguistics Circular 11(1983), 28-38.

\section{Moulin, A}

LSP dictionaries for EFL learners. In: RRK Hartmann (ed.) Lexicography: principles and practice. London: Academic Press. 1983. 144-152.

Nas, G

Visual word recognition in bilibguals: evidence for a cooperation between visual and soundbased codes during access to a commen lexical store. Journal of Verbal Learning and Verbal Behavior22(1983), 526-534. 


\author{
Nation, ISP \\ Teaching and Learning Vocabulary. Wellington: Victoria University. 1983. \\ Nation, ISP \\ Teaching and testing vocabulary. Guidelines 5(1983), 12-25. \\ Nation, ISP \\ Learning vocabulary. New Zealand Language Teacher 9,1(1983), 10-11.
}

\title{
Ndomba, D
}

Acquiring English vocabulary and structures: some procedures and problems. English Teaching Forum 21,2(1983), 18-24.

\section{Obler, LK}

La neuropsychologie du bilinguisme. [The neuropsychology of bilingualism.] Langages 72(1983), 33-43.

\section{Palmberg, R}

On the use of lexical avoidance strategies in foreign language communication. In: H Ringbom (Ed.) Psycholinguistics and Foreign Language Learning. Åbo: Åbo Akademi. 1983.

\section{Paradis, $M$ and $Y$ Lebrun}

La neurolinguistique du bilinguisme: representation et traitement de deux langues dans un meme cerveau. [The neurolinguistics of bilingualism: how two languages are represented in and processed by a single brain.] Langages 72(1983), 7-13.

\section{Perkins, K and SR Brutten}

The effects of word frequency and contextual richness on ESL student's word identification abilities. Journal of Research in Reading 6,2(1983), 119-128.

\section{Rapport, RL, CT Tan and HA Whitaker}

Fonctions linguistiques et troubles du langage chez les polyglottes parlant chinois et anglais. [Language function and dysfunction among Chinese- and English-speaking polyglots.] Langages 72(1983), 57-78.

\section{Rapport, RL, CT Tan and HA Whitaker}

Language function and dysfunction among Chinese- and English-speaking polyglots: Cortical stimulation, Wada Testing, and clinical studies. Brain and Language 18,2(1983), 342-366.

\section{Ringbom, $\mathrm{H}$}

Borrowing and Lexical Transfer. Applied Linguistics 4,3(1983), 207-212.

\section{Ringbom, $\mathrm{H}$}

On the distinctions of item learning vs system learning, and receptive competence vs productive competence in relation to the role of $\mathrm{Ll}$ in foreign language learning. In: H Ringbom (Ed.)Psycholinguistics and Foreign Language Learning. Åbo: Åbo Akademi. 1983.

\section{Rollinghoff, $\mathrm{A}$}

Das Schwere ist leichter: Bedeutungskomplexität als Lernhilfe beim Wörterlernen. [What's harder is easier: words with hard meanings can be easier to learn than easier ones]. In: F Hermans, W Lenschen and G Merkt (Eds) Lernziele Deutsch. Special Issue of Bulletin CILA 38(1983), 86-97.

\section{Rosenblum, $T$ and $S$ Pinker}

Word magic revisited: Monolingual and bilingual children's understanding of the word-object relationship. Child development 54,3(1983), 773-780.

\section{Schouten-van Parreren, C and M Hoogendoorn}

Het raden van de betekenis van onbekende woorden in een tekst. [Guessing the meaning of unknown words in a text.] Levende Talen, 382(1983), 266-270.

\section{Schulz, RA}

From word to meaning: foreign language reading instruction after the elementary course. Modern Language Journal 67(1983), 127-134. 


\section{Schwartz, RG and BY Terrell}

The role of input frequency in lexical acquisition. Journal of Child Language10(1983), 57-64.

\section{Steiglitz, EL}

A practical approach to vocabulary reinforcement. English Language Teaching Journal 37,1(1983), 71-75.

\section{Stromqvist, $\mathrm{S}$}

Lexical search games in adult second language acquisition: a model and some results. Gothenburg Papers in Theoretical Linguistics 44(1983).

\section{Swales, J}

Vocabulary work in LSP - a case of neglect? Bulletin CILA 37(1983), 21-31.

\section{Taeschner, $T$}

Does the bilingual child possess twice the lexicon of the monolingual child? Rassegna Italiana di Linguistica Applicata 15, 2/3(1983), 179-188.

\section{Tomaszczyk, J}

On bilingual dictionaries. In: RRK Hartmann (ed.) Lexicography: principles and practice. London: Academic Press. 1983. 42-52.

\section{Turner, G}

Teaching French vocabulary: a training study. Educational Review 35,1(1983), 81-88.

\section{Wagner, MJ and C Tilney}

The effect of 'superlearning techniques' on the vocabulary acquisition and alpha brainwave production of language learners. TESOL Quarterly 17,1(1983), 5-17.

\section{Walker, LJ}

Word identification strategies in reading a foreign language. Foreign Language Annals 16,4(1983), 293-299.

\section{Zatorre, $\mathbf{R}$}

La représentation des langues multiples dans le cerveau: vieux problèmes et nouvelles orientations. [The representation of several languages in the brain: new perspectives on old problems]. Langages 72(1983), 15-31.

As in 1982, most of this research was published by authors who contributed only a single source. Nation, the most prolific author in this year, contributed three items, three other authors (Carter, Meara and Ringbom) contributed two papers each. Binon and Cornu published the same paper twice, as did Rapport, Tan and Whitaker. The remaining authors each contributed to just a single paper.

\section{Analysis}

A total of 992 unique authors were cited in the 1983 literature, and the distribution of these citations is shown in Table 2. Table 2 shows that one source was cited in nine of the papers in the 1983 corpus, one author was cited eight times, three authors were cited seven times, and so on down to the 644 authors who were cited only once in the 1983 corpus. The most heavily cited authors in 1983 were Lambert (9), Michael West (8) and Albert, Obler and Pit Corder

Table 2: The distribution of citations in the 1983 corpus.

\begin{tabular}{|l|l|l|l|l|l|l|l|l|l|l|}
\hline frequency & 10 & 9 & 8 & 7 & 6 & 5 & 4 & 3 & 2 & 1 \\
\hline cases & & 1 & 1 & 3 & 4 & 10 & 18 & 55 & 156 & 644 \\
\hline
\end{tabular}


(7). Of these, only Lambert and West were also highly cited in the 1982 data, and this suggests that the significant influences in research are still relatively fluid at this time.

The figures in Table 2 tell us that a total of 92 authors are cited at least three times in this data. This figure is close to the standard figure of 100 authors which is commonly used in cocitation analyses, and the data that is reported in the following paragraphs is based on the cocitation links between these 92 authors. The data was analysed using the method summarised in Appendix 1, and mapped using the Gephi software (Bastian, Heymann and Jacomy, 2009). Gephi's output for the 1983 data is shown in Figure 1. Gephi identifies eight research clusters in the data, but really the data falls into two halves - the very large, densely connected cluster in the northeast corner of the map, and the several small clusters in the southwestern quadrant. These two halves are almost detached from each other, but a small number of nodes - notably Kucera and Francis - serve to keep the map as a connected whole.

Gephi's eight clusters can be characterised as follows:

Cluster I, the large cluster in the northeast sector of the map consists largely of researchers who are interested in neurolinguistics. Most of these co-citations come from a set of four papers that were published in a special issue of Langages, and the very dense pattern of citations in this cluster arises because almost all the papers refer to a small set of shared references in clinical linguistics: Albert and Obler's seminal book The Bilingual Brain (Albert and Obler 1979), some classical work by Pitres and Luria, and some more recent experimental studies by Lambert and his colleagues. None of this work is concerned with vocabulary learning and teaching, though it is interested in how bilingual speakers identify and process

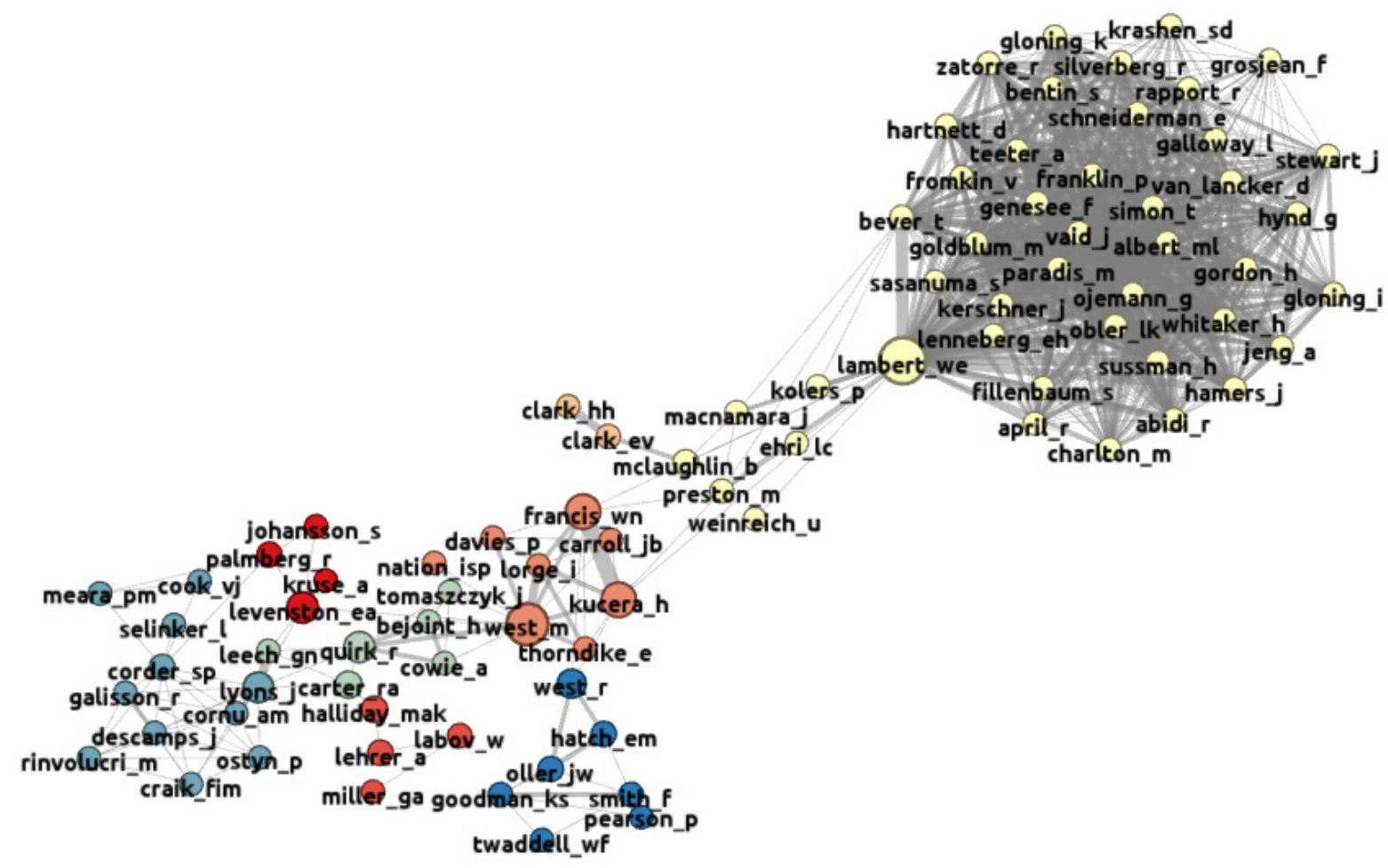

Figure 1. Co-citation analysis of 92 authors who are cited at least 3 times in the 1983 corpus. Links weaker than 2 are eliminated. Nodes are sized according to their betweenness centrality. 
stimuli in their two languages, how they keep them apart, and how these processes break down in bilingual aphasics. The small subcluster that projects from Lambert - Kolers, Macnamara, McLaughlin, Ehri and Preston - is a group of psychologists who are interested in the behaviour of bilingual subjects in experimental studies of language. Typically this subgroup does not use the clinical methods that are common to the rest of this cluster, relying instead on behavioural methods of enquiry.

Cluster II, the small cluster in the centre of the map consisting of Eve and Herbert Clark, is a Child Language Development cluster.

Cluster III, at the centre of the map - Kucera and Francis, Thorndike and Lorge, West, Davies and Nation - includes of a number of word frequency counts and word lists. The appearance of Paul Nation in this cluster is notable.

Cluster IV - R West, Hatch, Oller, Goodman, Smith, Pearson and Twaddell - is basically a reading cluster.

Cluster V, immediately to the West of cluster IV consists of Lehrer, Labov, Miller and Halliday. I think this is a cluster of people concerned with meaning and semantics.

Cluster VI, immediately North of Cluster V, consists of people who are working on corpora and dictionaries.

Cluster VII, Johansson, Palmberg, Kruse and Levenston, is the nearest thing in this map to a cluster which is primarily concerned with L2 vocabulary acquisition.

Cluster VIII at the Western edge of the map is the largest of the smaller groups. Its principal nodes are people who were associated with the Edinburgh approach to Applied Linguistics, together with other European scholars, notably Galisson, Cornu and Ostyn, who were working on pedagogical aspects of L2 vocabulary acquisition.

To make it easier to examine the dynamic features of the 1983 map, I have reproduced an analysis of the 1982 data in Figure 2. This analysis is slightly different from the data presented in my 2014 paper - the earlier paper used a threshold for inclusion which was lower than the threshold I have used for the 1983 data, and this makes it more difficult to make direct comparisons from one map to another. The map shown in Figure 2 uses the same data parameters as Figure 1, i.e. an inclusion threshold of at least three citations, and co-citation links which occur only once in the data set are deleted.

The fundamental structure of the 1982 map can still be seen in the 1983 map. Both maps consist of two halves which are relatively independent. In both maps, one of these halves is focused around the work of Lambert. However, the 1982 map contains a strongly connected cluster focused on Richards and Carroll, which is principally concerned with imagery and mnemonics in L2 vocabulary acquisition. This theme seems to have disappeared in the 1983 map. Instead, 1983 shows some restructuring of the word-list and frequency count cluster, and the appearance of a cluster of European vocabulary researchers. We also find formal 


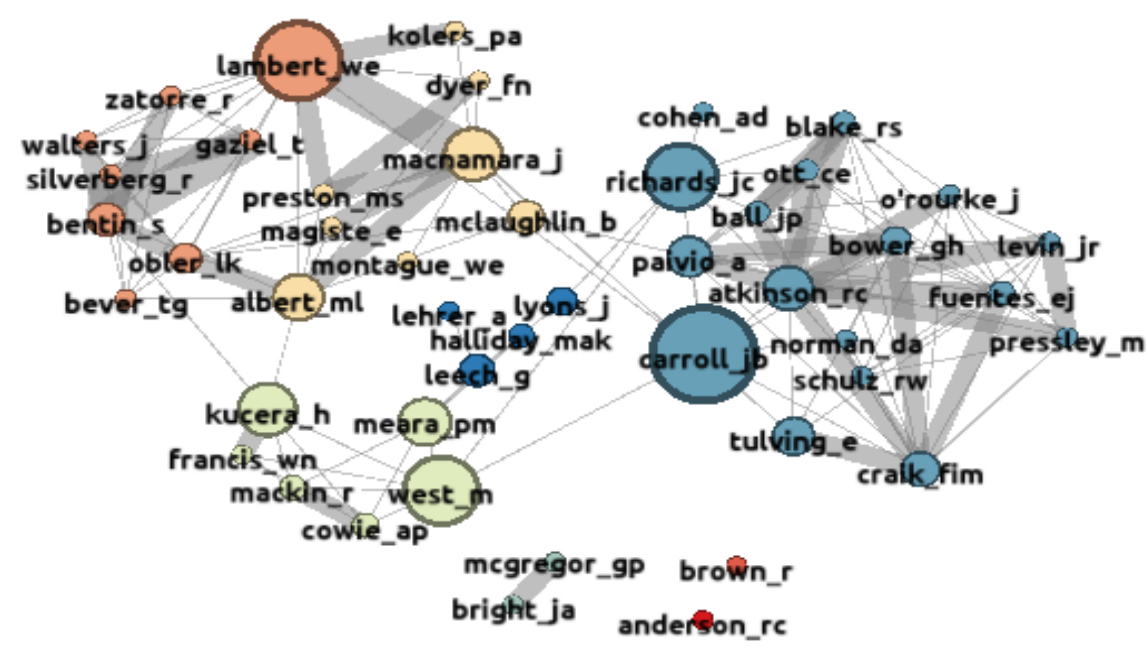

Figure 2: Co-citation analysis of 47 authors who are cited at least 3 times in the 1982 corpus. Links weaker than 2 are eliminated. Nodes are sized according to their betweenness centrality.

semantics and corpus research alongside L2 vocabulary research. Cluster IV, the reading cluster, represents a new strand in L2 vocabulary research.

The one outstanding difference between the two maps is the massive growth found in cluster I in 1983. Some work in neurolinguistics does appear in the 1982 map, but it was mainly concerned with experimental studies of word recognition, with a particular interest in non-roman scripts. The new cluster I is much more wide-ranging than this, and there has been a significant shift towards language pathology and neurolinguistics. It is notable that most of the names that were co-cited with Lambert in the 1982 map are not fully integrated into this new cluster. However, what is also very striking about this new cluster is that it has no links to other clusters in the map: none of the new sources in this cluster are co-cited alongside people located in the western end of the 1983 map. The most obvious interpretation of this patterning is that the few linguists working on L2 vocabulary acquisition do not seem to be aware of the sources that influence neurolinguistic research, or at least do not see its relevance for their own work. Similarly, the neurolinguists seem to be working in a bubble which does not make use of much linguistic research. Few of the names in Cluster I will be recognisable to linguists, and those that might be are mainly cited in the context of first language acquisition research. Obviously, there was an opportunity here for some cross disciplinary interaction, but we cannot tell from these maps whether interactions of that sort will indeed be a feature that we find in future maps. Intuitively, it seems that this window of opportunity was one whose significance was not realised at the time.

Figure 3 shows a simplification of Figure 1. This figure is based on the 1983 map, but includes only people who were significant both in 1982 and 1983 - the „survivors”. Half of the 47 people who appear in the 1982 map do not appear in the 1983 map - a figure which suggests that there is a great deal of churn in the work of the time. The co-citation patterns between the remaining 23 people who appear in both maps still give us a good idea of what the main strands of research are in 1983.

The broad outline of the 1982 map is also easily recognisable in this map: the coherent group of researchers surrounding Lambert, who work on the psycholinguistic behaviour of 


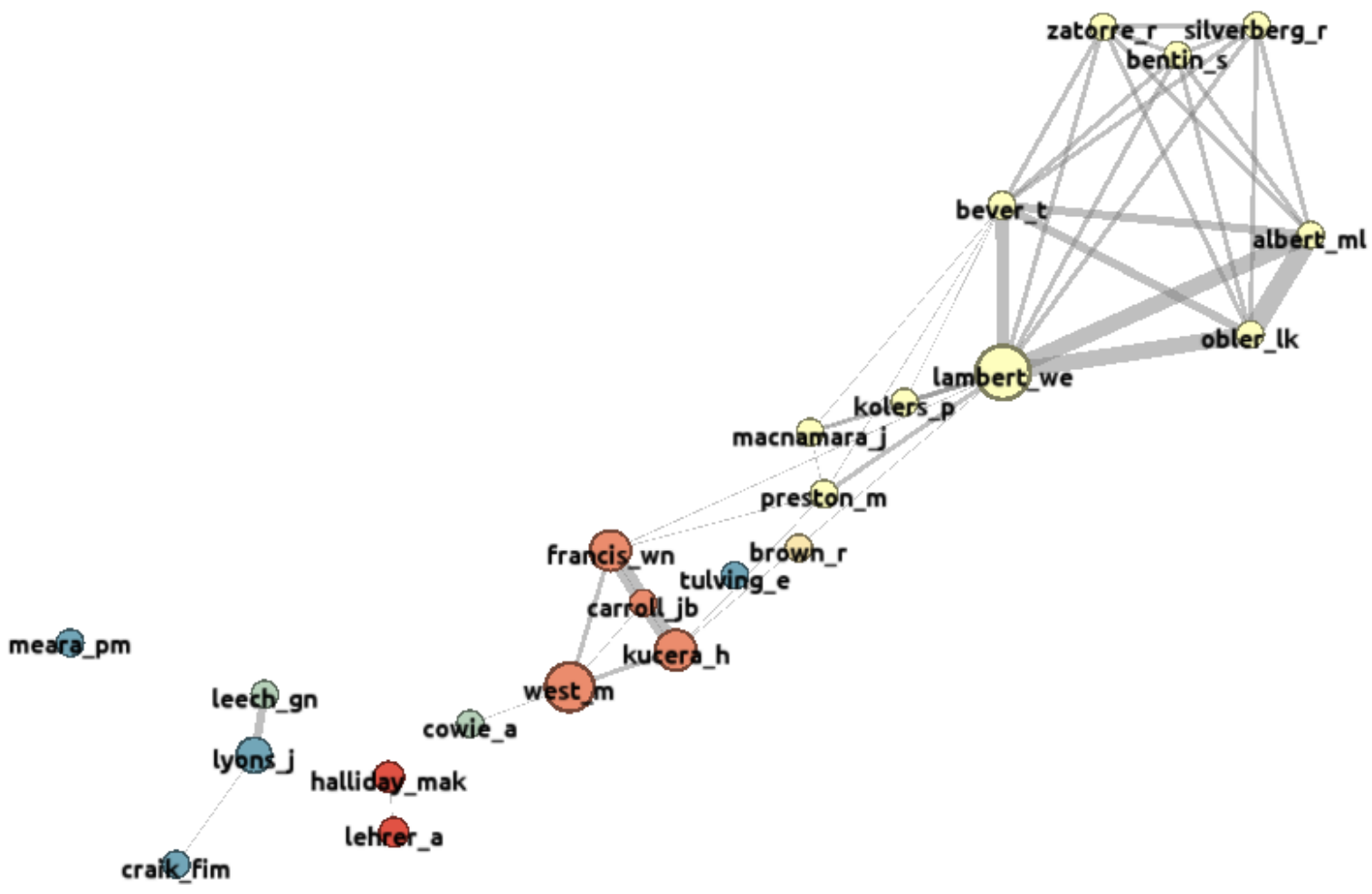

Figure 3: The Survivors: co-citation analysis of sources that appear in both the 1982 and the 1983 maps.

bilinguals, a set of word lists, and a ragbag of disconnected clusters that represent work on semantics and corpora. Tulving (in the centre of the map) represents work on the psychology of memory. Meara - the only name that is recognisably an L2 vocabulary acquisition researcher in this map - appears as an isolated outpost at the western edge of the graph, with no remaining connections to any of the other clusters.

We can also map out the co-citation relationships between the new sources who only appear in the 1983 graph, and this analysis is shown in Figure 4. Here, the 23 sources who appear in both the 1982 and the 1983 graph have been removed, and so that we are left with the co-citation relationships between the 69 new sources which appear only in the 1983 map. Figure 4 clearly highlights the growth points in research at this time. This growth is evenly divided between the neurolinguists and what we might broadly call sources in applied linguistics. However, the neurolinguists are clearly an organised research group with a common agenda, while the non-clinical sources are more disparate and less structured, and do not share a set of common reference points at this time. Only the new reading cluster shows any real signs of developing into a research front.

\section{Discussion}

In summary, then, 1983 is still very much part of the early formative period of modern L2 vocabulary research. The research being published is quite limited in scope, and there is no clear overarching research agenda in place. There has been some growth in research in this area - far more publications, and a richer set of co-citations, but most of this development 


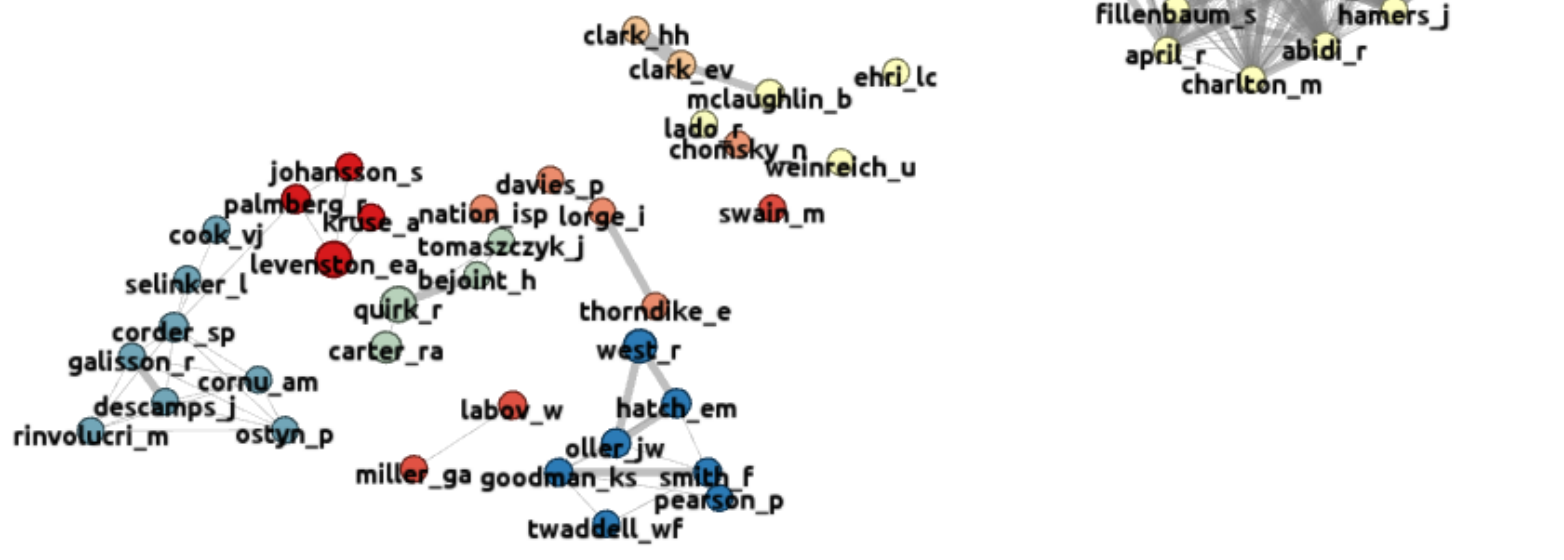

Figure 4: Co-citation analysis of the 69 new sources appearing in the 1983 map.

seems to have taken place in a way which has had little impact on the kind of research that was being carried out in 1982. Some work that was prominent in the 1982 data - notably the research on imagery and mnemonics - no longer figures as an active research feature.

One tantalising feature of this analysis is the appearance of Paul Nation as a new source in the 1983 data. Nation was the most prolific vocabulary researcher in this year, with three publications, including one book. He had also published extensively in earlier years, but his work at this stage is not influential enough for him to appear as a Highly Significant Influence in the co-citation maps. In later years, of course, Nation is a massive figure in vocabulary research, but in 1983 his influence remains quite limited. Significantly, 1983 saw the publication of Nation's book length treatment of issues in vocabulary learning and teaching (Nation 1983). This text was an early precursor of Nation's 1990 book, a text which set the agenda for vocabulary research in the 1990s and beyond. The 1983 text, however, was published by the English Language Institute at the Victoria University of Wellington, and remained difficult to get hold of. It had only a limited circulation, and for obvious reasons, it is not widely cited in the 1983 research literature. Nevertheless, Nation's 1983 book is really the first sign of a systematic account of modern vocabulary research. It marks the beginning of the end of this early piecemeal phase in vocabulary research, setting out a proper research agenda that eventually comes to dominate the field.

In the meantime, the strongest feature of the L2 vocabulary research scene is the vocabulary and reading cluster which is just beginning to emerge around this time. The new cluster seems to be well-grounded in L1 reading research (Smith, Goodman) and we can expect to see more work in this area in subsequent years. 
A feature which is less obvious at first sight is the presence of a significant number of researchers from continental Europe in Figure 4. The small cluster consisting of Johansson, Palmberg, Kruse and Levenston represents the beginning of a distinctively European approach to lexical errors and the analysis of learner output data. The small sub-cluster consisting of Galisson, Descamps, Cornu, and Ostyn represent a long-standing interest in vocabulary by French speaking researchers. Galisson's work is partly a reaction against some very influential research on „available vocabulary” carried out by Gougenheim and his colleagues in the 1970s (Gougenheim et al. 1964). This work is no longer apparent in the 1983 map - though it continued to be influential in other areas, notably Spain (Jimenez Catalan 2014). Ostyn's work develops a distinctive semantic approach to vocabulary teaching. (Rudzka, B, J Channell, Y Putseys and P Ostyn 1981, 1985).

Finally, it is worth noting the emergence of a small corpus linguistics and dictionaries cluster focused on Carter and Quirk. This type of research would become the defining characteristic of vocabulary research in the UK in the years to come.

\section{Conclusion}

This paper has presented a brief bibliometric analysis of L2 vocabulary research published in 1983. The analysis has identified a number of research clusters that were not present in the 1982 research but will become significant in later years, and highlights the volatility of vocabulary research at this time. The main contrast in the 1983 map is between the tightly organised research on neurolinguistics, which shares many common points of reference, and the much less organised, more heterodox research which researchers in L2 vocabulary acquisition cite. There is no evidence at this stage that a coherent approach to L2 vocabulary acquisition in emerging.

It is important to bear in mind that the analysis in Figure 1 is not a complete map of the research being carried out in 1983. The analysis is focused on 92 highly cited authors - people who are cited in at least three of the papers published in 1983. This criterion is quite loose: it means that the people appearing in the 1983 map were all cited in about 5\% of the research papers published in that year. There were, however, a large number of people who failed to meet this criterion, and their work does not appear in the map. Some of this work will turn out to be important in later maps.

\section{References}

Albert, M., and L. K. Obler (eds.). 1978. The bilingual brain: neuropsychological and neurolinquistic aspects of bilingualism. New York: Academic Press.

Bastian, M., S. Heymann, and M. Jacomy. 2009. Gephi: an open source software for exploring and manipulating networks. International AAAI Conference on Weblogs and Social Media.

French Allen, V. 1983. Techniques in teaching vocabulary. Oxford: Oxford University Press.

Galisson, R. 1983. Des mots pour communiquer: elements de lexicomethodologie. Paris: CLE.

Gougenheim, G. , R. Michéa, P. Rivenc, and A. Sauvageot. 1964. L'élaboration du français fondamental (Ier degré). Paris: Didier. 
Hellqvist, B. 2010. Referencing in the humanities and its implications for citation analysis. Journal of the American Society for Information Science and Technology 61: 310-318.

Jiménez Catalán, R. (ed.) 2014. Lexical availability in English and Spanish. Berlin: Springer.

Meara, P. M. 2012. The bibliometrics of vocabulary acquisition: An exploratory study. RELC Journal 43: 7-22.

Meara, P. M. 2014. Life before nation: Bibliometrics and L2 vocabulary studies in 1982. In M. Gómez González, F. J. Ruiz de Mendoza Ibañez, F. Gonzálvez García, and A. Downing (eds.), The functional perspective on language and discourse: applications and implications, 11-129. Amsterdam: John Benjamins.

Meara, P. M., 2014b. Vocabulary research in The Modern Language Journal: A bibliometric analysis. Vocabulary Learning and Instruction 3: 1-28.

Meara P. M. n.d. The vocabulary aquisition researach group archive. (VARGA) http://www.lognostics.co.uk/varga/

Nation, I. S. P. 1983. Teaching and learning vocabulary. Wellington: Victoria University.

Nation, I. S. P. 1990. Teaching and learning vocabulary. New York: Newbury House.

Price, D. 1965. Networks of scientific papers. Science 149 (3683): 510-515.

Rudzka, B., J. Channell, Y. Putseys, and P Ostyn. 1981. The words you need. London: Macmillan.

Rudzka, B., J. Channell, Y. Putseys, and P. Ostyn. 1985. More words you need. London: Macmillan.

Small, H. 1973. Co-citation in the scientific literature: A new measure of the relationship between two documents. Journal of the American Society for Information Science 24: 265-269.

White, H. D., and B. C. Griffith. 1981. Author cocitation: A literature measure of intellectual structure. Journal of the American Society for Information Science 32: 163-171.

\section{Appendix 1. Co-citation analysis}

The co-citation method was developed by Small in a number of papers published in the 1970s (e.g. Small 1973). This approach, which was actually built on earlier bibliometric work by Price (1965), has been extensively used to analyse research in the natural sciences (e.g., White and Griffith, 1981) but does not seem to have been adopted as a standard tool by researchers in the Humanities (Hellqvist, 2010).

The raw data for a co-citation analysis consists of a list of all the authors cited in the set of papers to be analysed. First we identify the literature that we want to analyse. Normal practice is to eliminate from this list bibliographies, monographs and theses, which tend to contain unusual citation patterns. This elimination leaves us with a set of research papers that cover the relevant topic or time span. Next we make a list of all the authors cited in each paper. Each author is listed separately, and co-authors all receive the same weight. Authors citing themselves are not penalised. From this author list, we can construct a list of co-citations - i.e. a list which identifies pairs of authors who are cited in the same work.

After this, we count the number of times a co-citation appears in this list, and eliminate the co-citations which appear only rarely. This simplifies the displays generated by the next procedure. The best results seem to emerge when the maps are not too dense. We therefore normally set the threshold for inclusion so that about 100 authors appear as nodes in the maps. We also eliminate the weaker co-citiation links so that the resulting map contains about 1000 edges.

Following this preparatory work, the list of eligible co-citations is submitted to GEPHI (http://gephi.org). GEPHI performs a cluster analysis on the co-citation data and generates a map which shows the relationships between the clusters. Each cluster consists of a number of authors who are frequently cited alongside each other. The clusters represent „invisible colleges” in the research community - a group of people who share common research interests. The specific focus of each cluster can usually be established by identifying the cluster members who figure in the largest number of co-citations for that cluster.

Some computer programs which facilitate the collection and analysis of co-citation data can be found on the Lognostics Tool Box web site: http://www.lognostics.co.uk/tools/ 